\title{
Hold your horses: Differences in EEG correlates of inhibition in cancelling and stopping an action
}

\author{
Mario Hervault a, *, Pier-Giorgio Zanone ${ }^{\text {a }}$, Jean-Christophe Buisson ${ }^{b}$, Raoul Huys ${ }^{\text {a }}{ }^{c}$ \\ ${ }^{a}$ Centre de Recherche Cerveau et Cognition, UMR 5549 CNRS, Université Toulouse 3 Paul Sabatier, France \\ ${ }^{\mathrm{b}}$ Institut de Recherche en Informatique de Toulouse, UMR 5505 CNRS, Université Toulouse 3 Paul Sabatier, France \\ ' Station d'Ecologie Théorique et Expérimentale, UAR 2029 CNRS, France
}

\section{A R T I C L E I N F O}

\section{Keywords:}

Action inhibition

Executive control

ERP

Time-frequency

Motor control

\begin{abstract}
A B S T R A C T
Behavioral adaptation to changing contextual contingencies often requires the rapid inhibition of planned or ongoing actions. Inhibitory control has been mostly studied using the stop-signal paradigm, which conceptualizes action inhibition as the outcome of a race between independent GO and STOP processes. Inhibition is predominantly considered to be independent of action type, yet it is questionable whether this conceptualization can apply to stopping an ongoing action. To test the claimed generality of action inhibition, we investigated behavioral stop-signal reaction time (SSRT) and scalp electroencephalographic (EEG) activity in two inhibition contexts: Using variants of the stop-signal task, we asked participants to cancel a prepared-discrete action or to stop an ongoing-rhythmic action in reaction to a STOP signal. The behavioral analysis revealed that the discrete and rhythmic SSRTs were not correlated. The EEG analysis showed that the STOP signal evoked frontocentral activity in the time and frequency domains (Delta/Theta range) in a task-specific manner: The P3 onset latency was the best correlate of discrete SSRT whereas N2/P3 peak-to-peak amplitude was the best correlate of rhythmic SSRT. These findings do not support a conceptualization of inhibition as action-independent but rather suggest that the differential engagement of both components of the N2/P3-complex as a function of action type pertains to functionally independent inhibition subprocesses.
\end{abstract}

\section{Introduction}

Inhibitory control is generally conceived of as a core executive function involved in the control of attention, thought, emotion, and action (Bari and Robbins, 2013; Diamond, 2013; Miyake et al., 2000). In particular, people are apt to cancel actions rapidly when unanticipated events or contextual changes occur. Some situations call for the inhibition of prepared actions, a case thoroughly studied by experiments using the stop-signal paradigm: some GO stimuli are unpredictably followed by a STOP signal requiring the cancellation of the prepared response (Logan and Cowan, 1984; Verbruggen et al., 2019). Other situations call for the abrupt cessation of ongoing actions during execution (Alegre et al., 2008; Lofredi et al., 2021). In this regard, previous experimental findings strongly suggest that the behavioral inhibition latency in the two situations are unrelated (Hervault et al., 2019). Still, it is unclear whether the neural processing of action inhibition relies on a single set of processes, that is, whether it is action-independent or action-specific. The present study addressed this issue by investigating behavioral stopping latency and scalp neural activity through EEG when participants inhibited either prepared-discrete or ongoing-rhythmic actions.

Based on the prevalent horse-race model (Logan and Cowan, 1984; Verbruggen et al., 2019), inhibition can be evaluated in stop-signal tasks as the outcome of a race between independent GO and STOP processes: it fails when the GO process finishes the race before the STOP process and succeeds otherwise. The grounding statistical model provides an elegant way to estimate the duration of the covert action inhibition process, the stop-signal reaction time (SSRT). The model remains silent, however, about the underlying neural processes. The stop-signal paradigm was developed as a tool to evaluate a presumably action-independent process of inhibition (Band and van Boxtel, 1999; Logan and Cowan, 1984). Logan and Cowan (1984, p. 318) could have been hardly more explicit about the presumption of generality when they stated that "The model developed so far is addressed to discrete tasks with discrete responses. It would seem to be relatively straightforward to generalize the model to continuous responses". Yet, for an ongo-

\footnotetext{
* Corresponding author. Cognitive Neurology Lab, Psychological and Brain Sciences, University of Iowa, 340 Iowa Ave, Iowa City, IA, 52242, United States.

E-mail address: mario-hervault@uiowa.edu (M. Hervault).
} 
ing-continuous action, the assumed race between the GO and STOP processes underlying the stop-signal paradigm cannot apply, since the GO (action initiation) process has long run to its completion at the time of the STOP Signal occurrence. This argument motivates our challenging the assumption that action inhibition is generic by comparing cancelling a prepared-discrete action and stopping an ongoing-rhythmic action. In addition, the investigation of ongoing-rhythmic action inhibition has been conceived as crucial in establishing the real-world generalizability of inhibitory control (Hannah and Aron, 2021). Studying ongoing-rhythmic action inhibition also provides the opportunity to measure the SSRT without relying on race-model assumptions (Lofredi et al., 2021; Morein-Zamir et al., 2006; Schultz et al., 2021).

Inhibitory control is indispensable in everyday life to stop either type of action. Discrete actions, like grasping, are delimited by moments without movement (i.e., with zero velocity and acceleration). That is, a discrete action unit refers to a movement that is preceded and followed by a non-negligible period in which the position of the moving limb does not change. In contrast, rhythmic actions, like walking, are continuous and periodic and lack such recognizable endpoints (Hogan and Sternad, 2007). The neural structures associated with controlling discrete and rhythmic actions differ considerably (Schaal et al., 2004; Spencer et al., 2003; Wiegel et al., 2020), due to differing timing and initiation mechanisms (Huys et al., 2008; Spencer et al., 2003). Thus, various lines of evidence persuasively suggest that discrete actions require additional control processes, involving supplemental brain activation as compared to rhythmic actions. Therefore, since discrete and continuous movements tap into distinct neural mechanisms of action control, they provide an excellent window to test whether inhibition is the action-independent process that it is often claimed to be (Logan and Cowan, 1984; Schall et al., 2017; Verbruggen and Logan, 2009a).

As of yet, only few studies have investigated whether the same inhibition process underwrites cancelling a prepared action or stopping an ongoing action. Morein-Zamir et al. (2004) found a correlation between the inhibition latencies (SSRTs) associated with cancelling a prepared action and stopping an ongoing (yet) isometric action in a rather peculiar task: Participants tracked the speed of a target that rotated along an imaginary circle on the screen by varying the pressure on a force sensor. Therefore, while the perceptual task was clearly continuous, there was hardly any movement to inhibit at all, since there was no limb displacement or trajectory to speak of. In contrast, a recent investigation showed that the SSRTs associated with cancelling a prepared-discrete key-pressing action (the classic stop-signal task) and stopping an ongoing-rhythmic drawing action were unrelated across participants (Hervault et al., 2019). This finding contradicts the assumption that a single mechanism is involved in inhibiting prepared and ongoing actions.

Regarding the electroencephalographic (EEG) neural activity related to action inhibition in the stop-signal paradigm, event-related potential (ERP) studies have linked inhibition to pronounced frontocentral negativity around 200-300 ms after the STOP-signal onset (N2), followed by a distinct positive activity about $150 \mathrm{~ms}$ later (P3) with a frontocentral to centroparietal topography (Huster et al., 2013). Suggestive of their functional relevance, the amplitude and latency of both waves differ between successful and failed STOP trials (e.g., Bekker et al., 2005; Kok et al., 2004). In addition, P3 onset latency correlates strongly with SSRT (e.g., Wessel and Aron, 2015). Finally, both N2 and P3 predict individual differences in inhibition performances (Chikara and Ko, 2019; Vahid et al., 2018). In the frequency domain, STOP trials reveal augmented power in the Delta $(0-3 \mathrm{~Hz})$ and Theta $(4-8 \mathrm{~Hz})$ frequency bands compared to GO trials (e.g., Chikara et al., 2014; González-Villar et al., 2016; Lavallee et al., 2014; Wessel and Aron, 2013). This difference is reliably discernible between 200 and $500 \mathrm{~ms}$ post stimulus presentation, that is, within the time range of the N2/ P3-complex (Huster et al., 2013).
These ERP and time-frequency patterns correlate significantly with action inhibition and proved to change with the loss of inhibitory control due to various disorders (Bekker et al., 2005; Kusztor et al., 2019; Lansbergen et al., 2007; Tschuemperlin et al., 2019; Van Voorhis et al., 2019). Whereas such correlations between inhibition performance and N2/P3 ERPs and the related time-frequency patterns are robust and reproducible, similar correlations have also been reported between these EEG indices and multiple other behavioral measures, thus questioning their specificity in indexing inhibitory processes per se (Huster et al., 2020). Hence, EEG correlates could either truly reflect a, say, "pure" inhibitory process (Hynd et al., 2020; Wessel and Aron, 2015), or the processing of the conflict required to inhibit action (Enriquez-Geppert et al., 2010), or a contextual update of the situation requiring a sporadic action revision (Waller et al., 2019). Thus, studying inhibition-related EEG patterns in tasks known to differ in the engaged action-control processes, as it is the case for discrete and rhythmic actions, may provide additional information to a functional interpretation of these EEG correlates.

Apart from classical stop-signal experiments, only two studies, to our knowledge, report that components of the N2/P3 complex are linked to the intentional termination of ongoing actions: The P3 wave was associated with ending sustained isometric elbow contraction (Hatta et al., 2003), while the N2 wave was related to the reactive cessation of an ongoing drawing action (Sosnik et al., 2015). In view of their presumed functional relevance, EEG correlates of inhibition constitute suitable candidates to address whether inhibitory processes are involved similarly in cancelling and stopping action. Indeed, EEG correlates of inhibition were modulated in amplitude and latency when the inhibitory requirement is varied by using stop-signal tasks, stop-change tasks, and GO/NoGO tasks (e.g., Krämer et al., 2011; Raud et al., 2020). Nonetheless, these studies reported EEG modulations when cancelling one action type only, again, discrete action, while there is, to our best knowledge, no study investigating modulations of inhibition EEG for continuous action. Therefore, no comparison across the two action types is possible in terms of neural inhibition modulations.

To sum up, the present study probes the assumption that action inhibition generalizes across action types by using tasks involving movements associated with distinct kinematics, dynamics, as well as neural control mechanisms. Therefore, we recorded EEG in participants who had either to cancel a prepared-discrete action or to stop an ongoing-rhythmic action performed on a digitizing tablet, while keeping the movement effector and the plane of motion the same. We investigated the frontocentral N2/P3-complex and Delta/Theta band activity as neural correlates of inhibitory action control.

\section{Materials and methods}

\subsection{Participants}

Twenty-three participants volunteered in the experiment. For three participants, behavioral and EEG artifacts warranted their exclusion from the final analysis, which was therefore restricted to twenty participants (12 males; 8 females, mean age $25 \pm 2.4$ (SD) years). All participants were healthy and had normal or corrected-to-normal vision. Participants' handedness was determined using the Edinburgh handedness inventory (Bryden, 1977) and only participants with a homogeneous pattern of right-hand preference were included. The study was conducted according to the principles stated in the Declaration of Helsinki and the procedures were approved by the local research ethics committee (ID-RCB: 2020-A03215-34). In order to be able to detect a difference interpreted as large (Cohen's $d=0.80$, Cohen, 1988; Sawilowsky, 2009) between discrete and rhythmic inhibition latencies, and by accepting a Type 1 risk $\alpha$ of 0.05 and a statistical power $1-\beta$ of 0.90 , the 
required number of participants for a repeated measures t-tests was estimated as minimally as 15 (using G*power software, Faul et al., 2009).

\subsection{Apparatus and stimuli}

Participants were seated in front of a graphic tablet (WACOM Cintiq $15 \mathrm{X}, 1280 \times 800$-pixel resolution). As an initial position, they put the stylus between two vertical yellow bands ( $1 \mathrm{~mm}$ wide) plotted at the center of the digitizing black screen (10 $\mathrm{mm}$ distant). Stimuli were green or blue $50 \mathrm{~ms}$ flashes displayed on the whole screen. Participants were requested to react to these stimuli by initiating swiping movements to the right or left direction in the discrete task and by continuous ongoing swiping oscillations in the rhythmic task. Occasionally, and unexpectedly (see Procedure), a red $50 \mathrm{~ms}$ flash followed the main stimulus, indicating the participants to stop the action. The $x$ and $y$ coordinates of the performed motions were digitized at a sampling frequency of $143 \mathrm{~Hz}$ as long as the stylus touched the tablet. The program controlling the tablet was custom-made. A hook-and-loop fastener was used to fix the participant's forearm to the table in order to restraint the movement to the wrist articulation, thereby avoiding large muscular noise in the EEG signal due to an intense contraction of the biceps and deltoid muscles.

\subsection{Procedure}

\subsubsection{Discrete task}

The discrete task (Fig. 1) was designed following guidelines to capture the ability to inhibit actions in stop-signal tasks (Verbruggen et al., 2019). The primary task was a two-choice reaction time task. When a green versus blue flash appeared, participants were instructed to reach to the right versus left half-side of the tablet screen, respectively, with the stylus (green and blue stickers were visible on the right and left tablet sides). On $75 \%$ of the trials (GO trials), only this main stimulus was presented, and the participants had to respond to the stimulus as fast and accurately as they could. On $25 \%$ of the trials (STOP trials), a red flash appeared shortly after the main stimulus as a STOP signal, which indicated to the participants to cancel their response (secondary task). This experiment consisted of one practice block and 30 experimental blocks, each consisting of 20 trials. Each trial began when the participant positioned the stylus between the two centered vertical lines, and the GO stimulus occurred after $1500 \mathrm{~ms}$. The time interval between GO stimuli of two subsequent trials was randomized between 3500 and $4000 \mathrm{~ms}$. In STOP trials, the GO stimulus was followed by the STOP signal after a delay (SOA; stimulus onset asynchrony). The SOA, initially set to $200 \mathrm{~ms}$, was dynamically adjusted in $50 \mathrm{~ms}$ increments

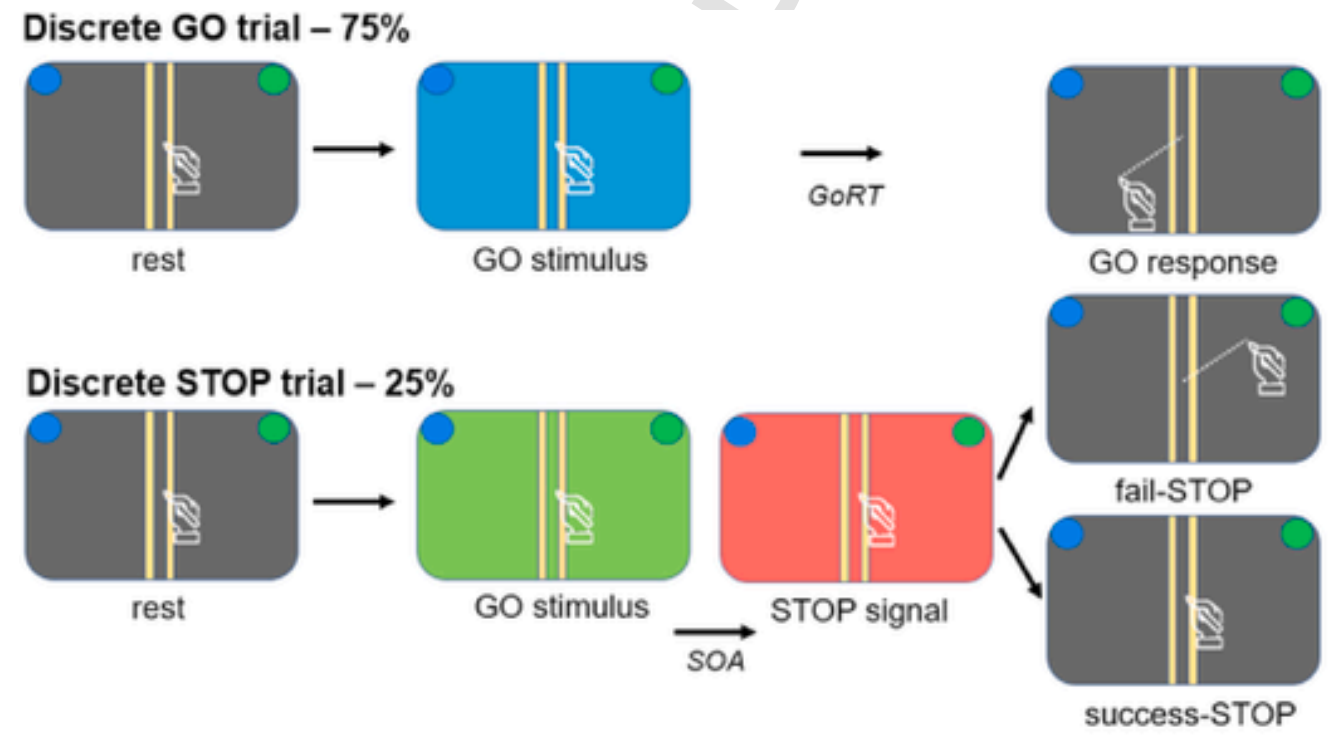

Rhythmic CONTINUE trial $-75 \%$

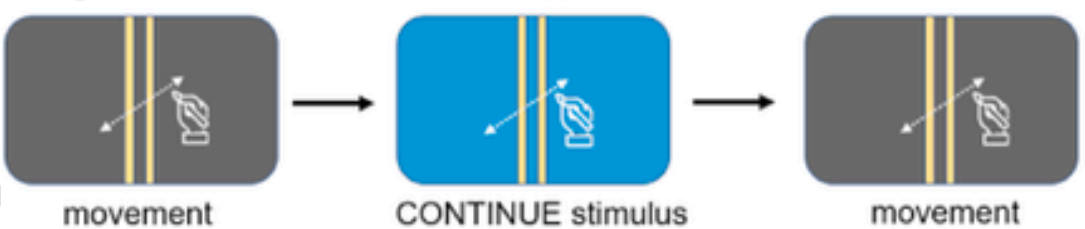

Rhythmic STOP trial - $25 \%$

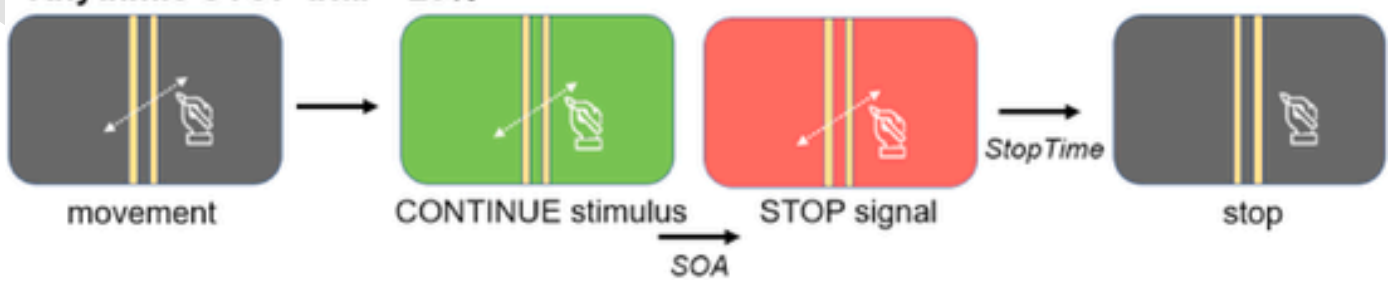

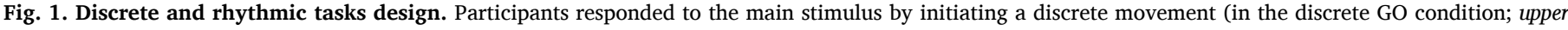

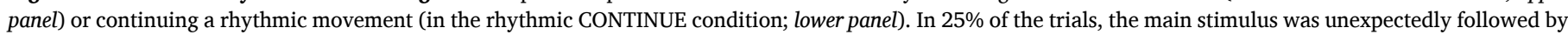
a STOP signal after a SOA, which was dynamically adjusted in the discrete task but fixed in the rhythmic one (see text). 
to achieve a probability of responding $p$ (respond|signal) of 0.50 . When the participant crossed a vertical line, the STOP trial was considered as a stop failure and the SOA was shortened; when the participant kept the stylus between the two lines, the STOP trial was considered successful and the SOA was prolonged. Participants were asked to focus on the primary GO task requiring as fast as possible swiping movements while minimizing errors. They were also instructed that in some STOP trials they would fail to cancel the response but that they should not be troubled by these failures.

\subsubsection{Rhythmic task}

The apparatus of the rhythmic task was the same, but the task design differed from the discrete task (Fig. 1). As a main task, participants were not engaged in a GO task but in a CONTINUE task. They were instructed to rhythmically oscillate the stylus between the two sides of the screen at a spontaneous frequency. A minimal and consistent oscillation amplitude was guaranteed by imposing the constraint that the oscillations' extrema had to fall outside the two centered vertical lines. The main task was to pursue the action without interruption when the green or blue CONTINUE stimuli appeared. In infrequent STOP trials, a red flash signal occurred after the main stimulus with a fixed SOA (see below). The participants were instructed to stop their ongoing-rhythmic action as soon as the STOP signal occurred and to wait for the next stimulus to restart the oscillation. The repartitioning between frequent CONTINUE trials (75\%) and improbable STOP trials (25\%) was similar to the discrete task, as well as the inter-trial duration. The task was also administered in 30 blocks of 20 trials.

For both tasks, the main stimulus was randomly a green or blue flash but with an equal probability within blocks. Participants had to maintain contact between the stylus and the tablet screen during the whole block. Participants were free to choose the rest time duration between the blocks (from 20s to 120s). They completed the discrete task in a first session and the rhythmic task in a second session one week later. This task order was chosen as it allowed us to set the fixed SOA between CONTINUE stimulus and STOP signal in the rhythmic task as the mean of the SOAs between GO stimuli and STOP signal obtained by each participant in the discrete task. This procedure ensured that the average delay between the main (GO/CONTINUE) stimulus and the secondary (STOP) signal were similar in both tasks, and so was the perceptual neural activity.

\subsection{EEG recording and preprocessing}

Scalp-EEG signals were acquired with $64 \mathrm{Ag} / \mathrm{AgCl}$ active pin electrodes at $2048 \mathrm{~Hz}$ (Biosemi Active Two 10/20 system). Data were referenced online with a CMS/DRL feedback loop and online low-pass filtered. Electrode offsets (difference in $\mathrm{mV}$ of each channel from the CMS electrode) were examined after electrode application, which was adjusted if the absolute value exceeded $15 \mathrm{mV}$. Three additional face electrodes recorded the vertical and the horizontal electrooculograms. Digital markers (event codes) were inserted into the continuous EEG via a DB25 cable through a parallel port interface. Continuous EEG data were imported and preprocessed in bespoke scripts using functions from the EEGLAB Matlab plugin (Delorme and Makeig, 2004). Data were downsampled to $500 \mathrm{~Hz}$, high-pass filtered at $0.1 \mathrm{~Hz}$, and low-pass filtered at $50 \mathrm{~Hz}$ with a linear finite impulse response filter. EEG epochs corresponding to task trials were generated by extracting data from -1000 to $2000 \mathrm{~ms}$ around each main stimulus event (GO or CONTINUE stimulus onset for the discrete and rhythmic task, respectively). After epoching, the recording was visually inspected for non-stereotypical artifacts (such as muscle activation or intermittent electrode artifacts) and any epoch found to contain an artifact was removed from the data. EEG was finally re-referenced to the average of all channels. Independent component analysis (Infomax ICA; Bell and Sejnowski, 1995) was applied to continuous EEG data (concatenation of the EEG epochs) to identify neural components contributing to the observed scalp data. In the original scalp 64-channel data, each row of the data matrix represents voltage, summed between source projections to one data channel. After decomposition (64 components), each row of the data matrix gives the time course of the activity of one component process spatially filtered from the channel data (Delorme and Makeig, 2004). Using the ICLABEL classifier (Pion-Tonachini et al., 2019) over the 30 first components, components identified as artifactual, i.e., with less than $5 \%$ chance to account for neural activity, were removed from the EEG data structure, thus removing their contributions to the observed EEG. Rejection was systematically checked by visual inspection of component properties (time series, spectra, topography) according to ICLABEL guidelines (Pion-Tonachini et al., 2019), leading to an average number of 7 components rejected by participant $(\mathrm{min}=4 \mathrm{ICs}$, $\max =9 \mathrm{ICs}$ ). Across all participants, these procedures led to the omission of $8.8 \%$ of the STOP trials in the discrete task $(\mathrm{SD}=1.6 \%)$ and $4.1 \%$ of the rhythmic STOP trials $(\mathrm{SD}=1.7 \%)$.

\subsection{Behavioral measures}

Data analyses were performed using Matlab ${ }^{\mathrm{TM}}$ software (Mathworks 2013).

\subsubsection{Discrete stop task}

Reaction times (RTs) were computed for both action initiation and inhibition. For each GO trial, GoRT was calculated as the time between the GO stimulus onset and the response onset, the latter being defined as the moment the swipe had exceeded $5 \%$ of the Euclidean distance between the initial and furthest (i.e., end) position of the movement response. The discrete stop-signal reaction time (SSRTd) was computed using the integration method with replacement of GO omissions, which entails selecting the $n$th GoRT, where $n$ equals the number of RTs in the GoRT distribution multiplied by the overall p(respond|signal). The SSRTd is then obtained by subtracting the mean SOA from the $n$th GoRT (Verbruggen and Logan, 2009a) (Fig. 2). The SSRTd could be estimated for all of the 20 participants as their $p$ (respond|signal) did not differ significantly from 0.50 (see Results). Fail-STOP RT was computed as the reaction time measured in failed STOP trials (FsRT).

\subsubsection{Rhythmic stop task}

In each STOP trial, the SSRT (SSRTr) was computed using the methodology developed in a previous study (Hervault et al., 2019). Briefly, stop time was calculated as the latency between the STOP signal onset and the end of the action, identified when the motion velocity reduced to null following the STOP signal. Within the stop time, SSRTr was calculated as the latency between the STOP signal onset and the onset of the response adjustment (Fig. 2). This time point was defined as the moment the ongoing trajectory in phase space (i.e., the space spanned by $\mathrm{x}$ and $\mathrm{dx} / \mathrm{dt}$ ) deviated relative to movements without a STOP signal according to statistical criteria based on a sample's position in phase space, and the angle and magnitude of its corresponding velocity vector (Hervault et al., 2019).

\subsection{Scalp activity measures}

The neural network engaged in inhibitory control (Aron, 2007; Lofredi et al., 2021) has been mainly associated to ERPs and timefrequency power visible at frontocentral sites, when investigated using EEG (Chikara et al., 2014; González-Villar et al., 2016; Huster et al., 2013; Lavallee et al., 2014; Wessel and Aron, 2013, 2015). According to this literature, the following analyses were performed using the three $\mathrm{FCz}, \mathrm{Cz}$ and $\mathrm{CPz}$ EEG channels. In addition, the occipital Oz channel was added to the ERP analysis to evaluate the potential contribution of the attention in our task comparison. Especially, the visual N1 wave reflects the operation of a discrimination process within the focus of at- 


\section{DISCRETE STOP TRIALS}
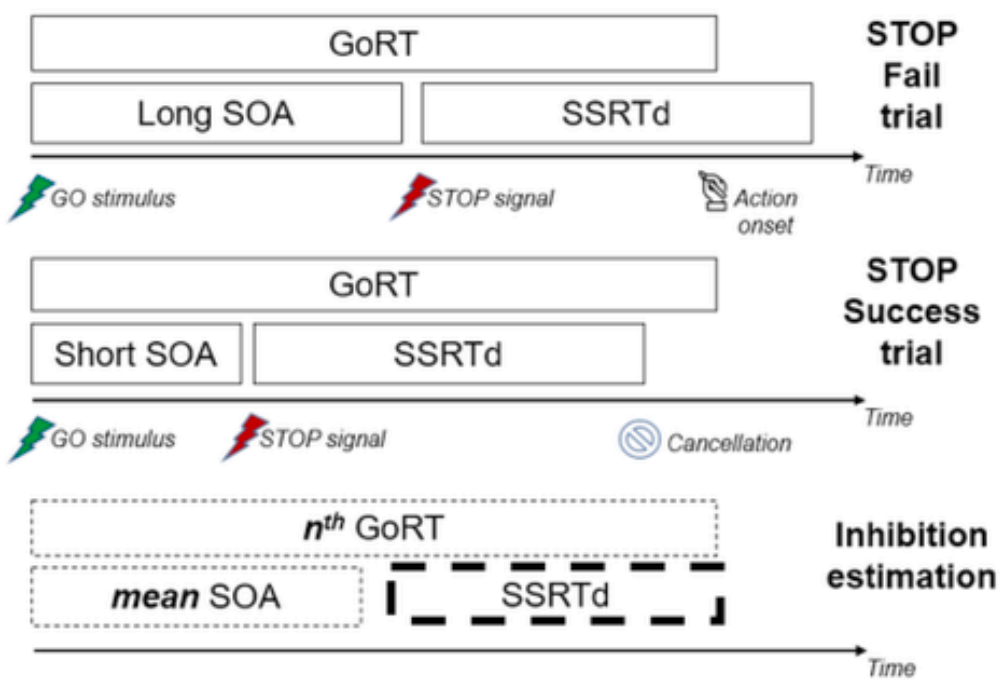

RHYTHMIC STOP TRIALS

\begin{tabular}{|c|c|c|}
\hline Ongoing Movement & Stop Time \\
\hline fix SOA & SSRTr \\
\hline PCONTINUE stimulus & $\begin{array}{c}\text { Movement } \\
\text { Deviation }\end{array}$ & (A) Stop signal
\end{tabular}

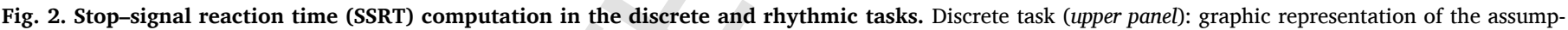

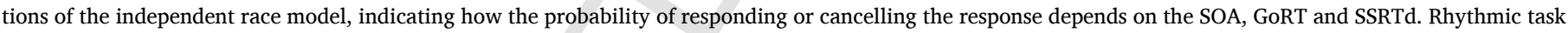

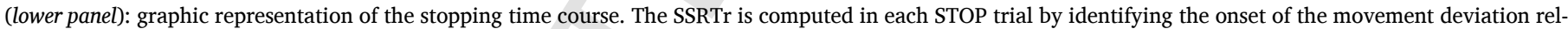
ative to movements without a STOP signal (see text).

tention. Indeed, N1 appears to be larger when participants are performing discrimination tasks than when they are performing detection tasks (Vogel and Luck, 2000).

\subsubsection{Event-related potentials}

For the main task's ERP, we averaged the EEG time series locked to the main stimulus onset (GO or CONTINUE) following the subtraction of a -200 to $0 \mathrm{~ms}$ pre-stimulus period as baseline. As STOP trials contained both the main stimulus (GO or CONTINUE) and the subsequent STOP signal, the STOP-signal-locked ERP cannot be directly and reliably computed as it may be contaminated by residual main-stimulus related activity (if not removed by the averaging process; Woldorff, 1993). For the rhythmic task, this overlapping problem was overcome by computing the neural activity difference of the main-stimulus locked ERP between STOP trials and CONTINUE trials, and then relocking the STOP trial ERP to the STOP signal onset. This procedure, however, cannot be used for the discrete task, where the SOA delay (duration between GO stimulus and STOP signal) was adjusted across trials. To assess differences in the STOP-signal-processing irrespective of differences in the GO-stimulus processing, we computed, for the discrete task, the difference EEG activity separately for successful and failed STOP trials, in a similar manner as in previous studies (see Krämer et al., 2011; Ramautar et al., 2004, 2006). Specifically, GoRTs associated with the GO trials were rank-ordered, and then split into two parts. According to the horse-race model the fast and slow tails of the GoRTs distribution corresponded to the proportion of failed and successful STOP trials, respectively (Verbruggen and Logan, 2009a). Thus, ERPs were averaged across slow GO trials. This "virtual" GO-trials-ERP was then subtracted from successful STOP trials EEG data. STOP trials ERP was then computed and re-locked to the
STOP-signal-onset accounting for the SOA delay of the successful STOP trials.

\subsubsection{Time-frequency analysis}

The EEG signals were convolved with complex 3 to 8-cycle-long Morlet's wavelets. Their central frequencies were changed from 0.5 to $50 \mathrm{~Hz}$ in $0.5 \mathrm{~Hz}$ steps. From the wavelet transformed signal, $w_{k}(t, f)$, of trial $k$ at time $t$ ( $2 \mathrm{~ms}$ time resolution) and with frequency $f$, the instantaneous power spectrum $p_{k}(t, f)=R\left(w_{k}(t, f)\right)^{2}+I\left(w_{k}(t, f)\right)^{2}$ and instantaneous phase $\varphi_{k}(t, f)=\arctan \left\{I\left(w_{k}(t, f)\right) / R\left(w_{k}(t, f)\right)\right\}$ were extracted ( $R$ and $I$ symbolize the real and imaginary parts of a complex number, respectively). Using the instantaneous power spectrum, $p_{k}(t, f)$, the average power spectrum was computed for each participant in the GO, CONTINUE, and STOP conditions as follow:

Power $=\frac{1}{N} \cdot \sum_{k=1}^{N} p_{k}(t, f),(N=$ number of trials $)$.

As for the ERPs computation, GO and CONTINUE Power was subtracted from its respective STOP trials results (see above). Power was then normalized with respect to a -500 to $-200 \mathrm{~ms}$ pre-stimulus baseline and transformed to decibel scale $\left(10 \cdot \log _{10}\right.$ of the signal).

\subsubsection{Statistical analysis}

To assess differences in the STOP-signal related neural activity between discrete and rhythmic action stopping, we subjected the individual ERP vectors and Power matrices to a non-parametric permutation procedure (Maris and Oostenveld, 2007). For this purpose, the 0-800 ms time window of the participants' STOP-signal locked ERP was 
used. Regarding the individuals' Power matrices, we used a similar time-window associated with a $2-8 \mathrm{~Hz}$ frequency-window. These windows contains both the time (N2/P3) and frequency ranges (Delta/ Theta) of interest to investigate inhibitory processes (Huster et al., 2013). A 0-300 ms window was used for the occipital Oz ERP permutation testing.

ERPs of a given EEG channel were subjected to a non-parametric permutation procedure, at the group level (Maris and Oostenveld, 2007). The 20 participants' windowed ERPs were pooled over the two STOP conditions ( 20 by conditions). Two sets of 20 ERPs each were then drawn randomly from this pool, and the differential grand-average ERP was computed between the two sets. This procedure was repeated 10000 times, thus producing a distribution of these ERPs based on shuffled data under the null hypothesis. For each time point, a $p$-value was computed as the proportion of these pseudo-differential ERPs that exceeded the observed participants' average differential ERP. This $p$ value thus indicates at which time point the observed power distribution for the two conditions is more divergent than expected for random data ( $p=.05$ threshold). To correct for multiple comparisons, we analyzed the resulting distributions of $p$-values to compute $p$-thresholds corresponding to the 2.5 th percentile of the smallest, and the 97.5th percentile of the largest $p$-values distribution (Cohen, 2014). This permutation analysis was similarly applied to each time-frequency point to assess the Power matrices significance between the two STOP conditions.

Next, brain-behavior correlations were computed. For each of the three frontocentral channel ERPs, N2 peak amplitude was computed by searching for the local peak with the minimal value in the $100-300 \mathrm{~ms}$ time range. N2 onset latency was defined as the time when half of the N2 peak amplitude value was reached (Lopez-Calderon and Luck, 2014). Peak amplitude and onset latency were computed in the same way for the P3 wave but now by searching for the maximal value in the 200-500 ms range. ERP peak and onset detection were visually checked for each participant and each channel. In addition, the N2/P3 peak-to-peak amplitude was computed. Each of these five measures was then subject to a Pearson correlation test with the behavioral SSRT value. Resulting $p$-values were corrected using Bonferroni correction, that is, by multiplying each $p$-value by the number of tests (i.e., five). Similarly, time-frequency Power peak amplitude and peak latency were computed and correlated to SSRT using the same correction (two tests).

\section{Results}

\subsection{Behavior}

Main behavioral results are reported in Table 1. Importantly, FsRT $(\mathrm{M}=424 \mathrm{~ms}, \mathrm{SD}=51 \mathrm{~ms})$ was significantly shorter than GoRT $(\mathrm{M}=474 \mathrm{~ms}, \mathrm{SD}=58 \mathrm{~ms}$ ) for each single participant (paired-t-tests, $p<.01)$. The participants' $p$ (respond $\mid$ signal) $(\mathrm{M}=0.53, \mathrm{SD}=0.08)$ was not significantly different from $0.50\left(t_{(19)}=0.33, p=.74, \mathrm{CI}_{95}\right.$ $[0.44,0.61]$, Cohen's $d=0.37$ ), and this probability increased sigmoidally with the SOA (i.e., the inhibition function). These analyses confirm the validity of the race-model between GO and STOP processes

Table 1

Main Behavioral measures of the two tasks (Mean and SD values).

\begin{tabular}{lll}
\hline & Discrete Task & Rhythmic Task \\
\hline GoRT & $474 \mathrm{~ms}(58)$ & $/$ \\
GO omission rate & $.99(.01)$ & $/$ \\
GO error rate & $.03(.05)$ & $/$ \\
Movement frequency & $/$ & $1.6 \mathrm{~Hz}(0.55)$ \\
SOA & $206 \mathrm{~ms} \mathrm{(73)}$ & $206 \mathrm{~ms}(73)$ \\
p(respond|signal) & $.53(.08)$ & $/$ \\
FSRT & $424 \mathrm{~ms}(51)$ & $/$ \\
Stop Time & $/$ & $400 \mathrm{~ms} \mathrm{(31)}$ \\
SSRT & $268 \mathrm{~ms}(52)$ & $270 \mathrm{~ms} \mathrm{(24)}$ \\
\hline
\end{tabular}

in the discrete task, validating the computation of the SSRTd in accordance with the model. In the rhythmic task, the spontaneous oscillation frequency was $1.60 \mathrm{~Hz}$ on average $(\mathrm{SD}=0.55 \mathrm{~Hz}$ ). Previous studies have shown that movement performed at this frequency were continuously rhythmic (Hermes et al., 2012; Seeber et al., 2016; Toma et al., 2002) and that the stopping latencies computed in the same task was not dependent of the movement phase (Hervault et al., 2019). The participants' mean Stop Time $(\mathrm{M}=399, \mathrm{SD}=34 \mathrm{~ms})$ and mean SSRTr $(\mathrm{M}=268, \mathrm{SD}=24 \mathrm{~ms})$ correlated strongly $\left(\right.$ Pearson $r_{(18)}=0.78$, $\left.p<.001, \mathrm{CI}_{95}[-0.52,0.91]\right)$, which underlines the contribution of the inhibition process in the final stopping performance. Across the 20 participants, the SSRTd $(\mathrm{M}=268 \mathrm{~ms}, \mathrm{SD}=52 \mathrm{~ms})$ pertaining to the discrete task and the SSRTr $(M=270 \mathrm{~ms}, \mathrm{SD}=24 \mathrm{~ms})$ pertaining to the rhythmic one did not differ (paired $t$-test, $t_{(19)}=-0.08, \mathrm{p}=.93, \mathrm{CI}_{95}$ [ $-23 \mathrm{~ms}, 21 \mathrm{~ms}], d=0.05)$. Crucially though, the inhibition times of both tasks were unrelated across participants $\left(r_{(18)}=-0.04, p=.86\right.$, $\mathrm{CI}_{95}[-0.47,0.41]$, Fig. 5). As a validity check, we next verified whether for the rhythmic task the SSTRr values measured in the first 15 blocks of trials versus the second 15 blocks of trials were correlated, and found a positive significant correlation $\left(r_{(18)}=0.81, p<.001, \mathrm{CI}_{95}[-0.56\right.$, $0.92]$ ). To ensure that participants did not proactively anticipate the STOP signal occurrence, we tested whether the rhythmic movement was slow down at the SOA latency (Schultz et al., 2021). Including all the rhythmic STOP trials of our participants, we compared the movement mean velocity of the $100 \mathrm{~ms}$ time window surrounding the STOP signal occurrence $(-50 \mathrm{~ms}$ to $+50 \mathrm{~ms})$ to the movement mean velocity of the $100 \mathrm{~ms}$ time window surrounding the CONTINUE stimulus occurrence. This comparison (paired $t$-test) failed to show a significant difference between the two time windows for both the $\mathrm{x}$-velocity $(t$ $\left.{ }_{(2709)}=-0.10, p=.92\right)$ and y-velocity $\left(t_{(2709)}=0.47, p=.64\right)$, indicating that the participants did not proactively adapt their movements in either movement dimension.

\subsection{EEG time domain}

The ERP analysis showed that both N2 and P3 waves were evoked in the two stop-signal tasks, yet with clear differences between the discrete and rhythmic actions (Fig. 3). Indeed, the permutation analysis identified a significantly higher voltage in the discrete STOP condition as compared to the rhythmic STOP condition in the $218-458 \mathrm{~ms}$ time window at $\mathrm{FCz}$, in the $204-450 \mathrm{~ms}$ time window at $\mathrm{Cz}$ and in the 202-254 ms time window at CPz ( $p<.05$, corrected). The topographies of the ERP plotted at N2 and P3 peak latency (Fig. 3) confirmed the frontocentral locus of the evoked activity, excepted for the N2 discrete STOP condition for which the small amplitude was associated to a less focused activity. In contrast, the $\mathrm{Oz}$ site showed a lower voltage in the discrete STOP condition, as compared to the rhythmic one, which was significant in the $228-280 \mathrm{~ms}$ time window. This difference was present after the early, negative, N1 wave (Fig. 3), probably occurring later than perceptual detection of the STOP signal (Hillyard et al., 1998; Luck, 2014).

The N2 and P3 peak values and onset latencies, as well as the N2/P3 peak-to-peak value were computed for each of the three frontocentral channels $(\mathrm{FCz}, \mathrm{Cz}, \mathrm{CPz}$ ) and correlated to behavioral inhibition latencies. Mainly, at FCz site P3 onset latency was significantly correlated to SSRT in the discrete STOP condition $\left(r_{(18)}=0.69\right.$, corrected $p<.01$, $\mathrm{CI}_{95}$ [0.35, 0.87], Fig. 5) but not in the rhythmic one $\left(r_{(18)}=0.15\right.$, $\left.p=.52, \mathrm{CI}_{95}[-0.31,0.55]\right)$. In contrast, the N2/P3 peak-to-peak latency was significantly correlated to SSRT in the rhythmic STOP condition $\left(r_{(18)}=-0.57\right.$, corrected $\left.p=.04, \mathrm{CI}_{95}[-0.81,-0.17]\right)$ but not in the discrete one $\left(r_{(18)}=-0.21, p=.37, \mathrm{CI}_{95}[-0.59,0.25]\right)$. SSRT correlation with $\mathrm{P} 3$ onset latency was also significant at the $\mathrm{Cz}$ site in the discrete STOP condition $\left(r_{(18)}=0.50\right.$, corrected $p=.02, \mathrm{CI}_{95}[0.08$, 0.77]). No other ERP-behavior correlation was significant. 

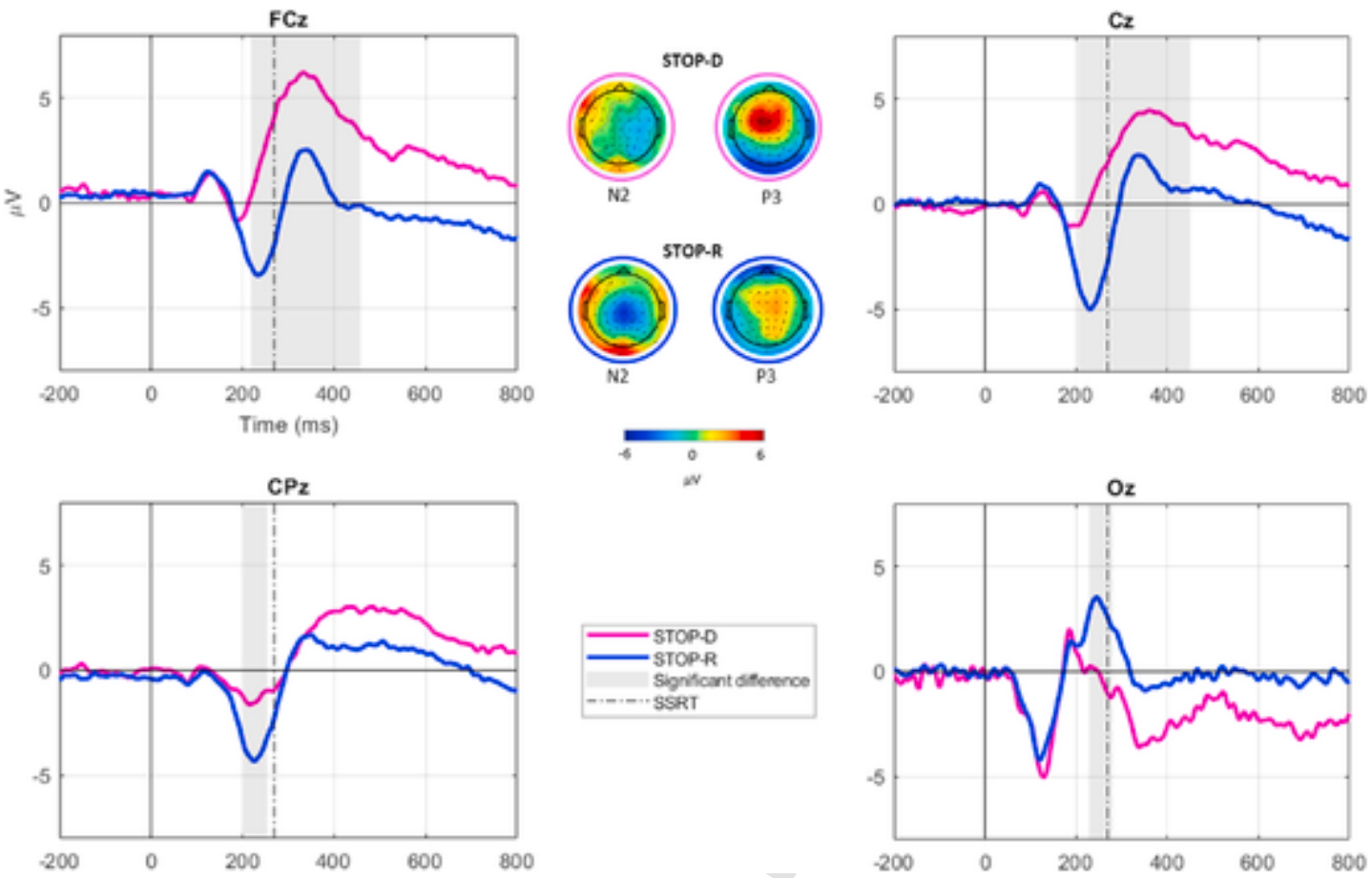

Fig. 3. EEG time-domain analysis of STOP trials. Grand average STOP-signal locked ERPs in the discrete (STOP-D) and rhythmic (STOP-R) STOP conditions with associated topographies averaged across participants at FCz ERPs peak latencies. ERPs are displayed for three frontocentral (FCz, Cz, CPz) and one occipital $(\mathrm{Oz})$ midline channels. In grey, the regions of significant difference (according to the nonparametric permutation analysis) between discrete (successful) and rhythmic STOP conditions $(p<.05$, corrected).

\subsection{EEG time-frequency domain}

The grand average Delta/Theta-window STOP-signal locked power maps are displayed in Fig. 4. A clear frontocentral power increase was present in the Delta/Theta range after STOP signal occurrence, with differences between discrete and rhythmic conditions. Indeed, the permutation analysis identified a significantly higher power in the discrete
STOP condition as compared to the rhythmic STOP condition for timefrequency points included in a $3.5-6.5 \mathrm{~Hz} / 128-368$ window at $\mathrm{FCz}$, in a $4.5-7 \mathrm{~Hz} / 268-382$ window at $\mathrm{Cz}$ and a $4-7.5 \mathrm{~Hz} / 212-376$ window at $\mathrm{CPz}(p<.05$, corrected, Fig. 4).

The Power peak values and latencies were computed for each of the three frontocentral channels $(\mathrm{FCz}, \mathrm{Cz}, \mathrm{CPz})$ and correlated to behavioral inhibition latencies. Power peak latency was significantly correlated to
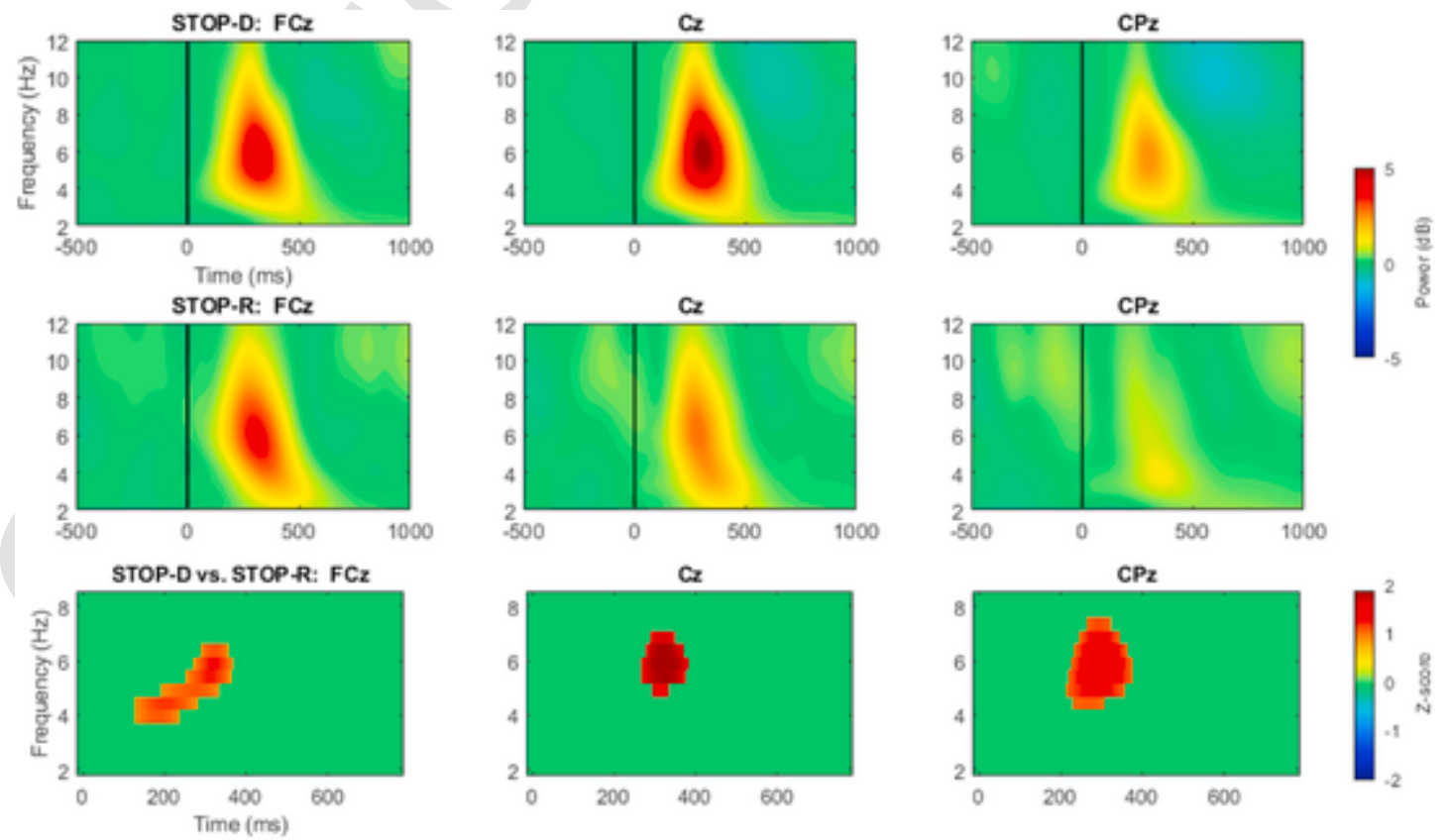

Fig. 4. FCz time-frequency analysis of STOP trials. Grand averaged STOP-signal locked Power maps for the discrete and rhythmic STOP conditions. The differential Power maps thresholded after the permutation procedure $(p<.05$, corrected) are associated to different frequency ( $2-8 \mathrm{~Hz})$ and time ( $0-800 \mathrm{~ms})$ ranges that correspond to the time-frequency window included in the permutation statistical analysis. Red indicates significantly increased activity (two-sided $p$, upper tail) in the discrete compared to the rhythmic task. (For interpretation of the references to colour in this figure legend, the reader is referred to the Web version of this article.) 

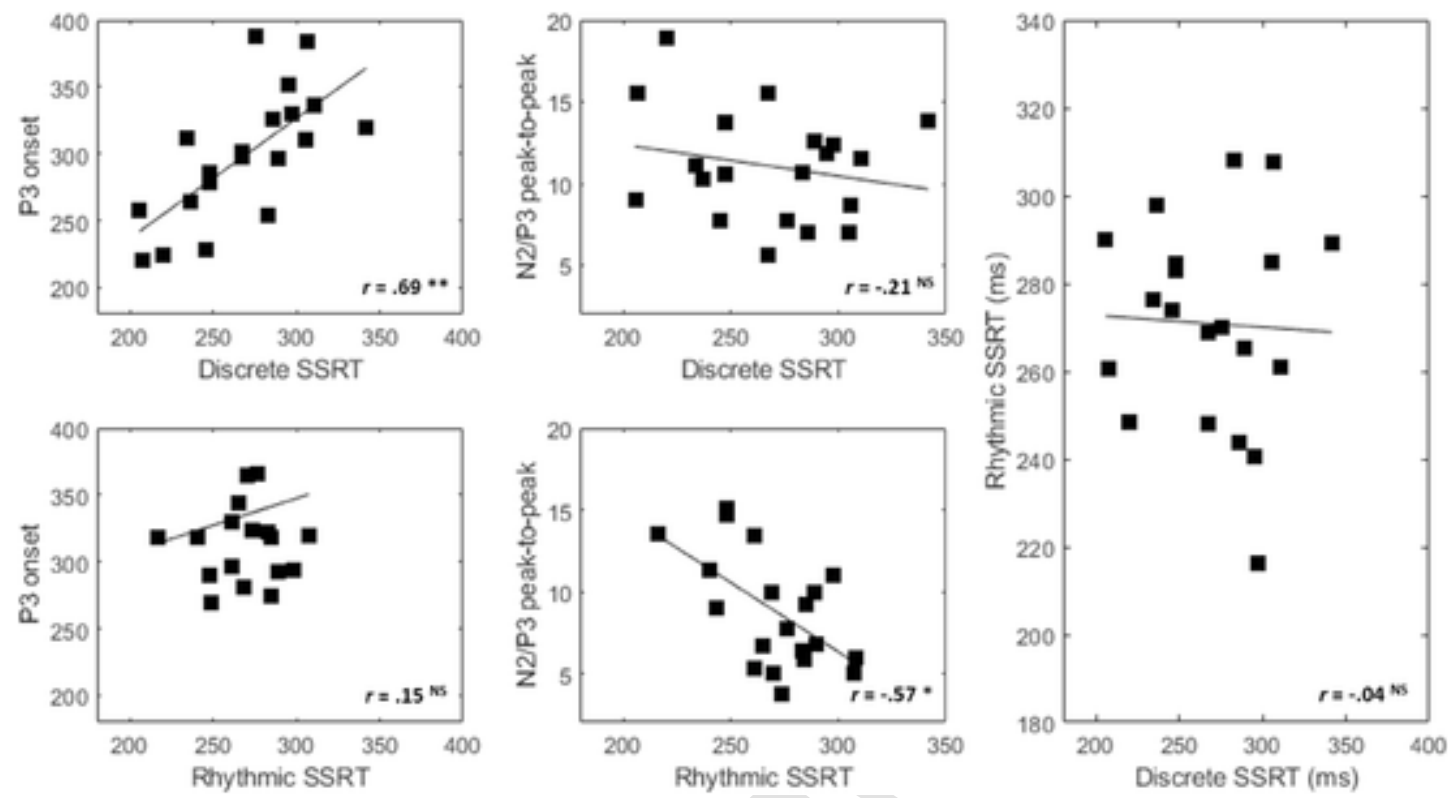

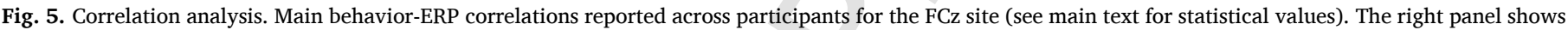

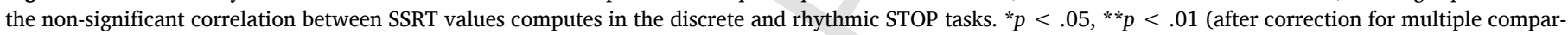
isons), ${ }^{\mathrm{NS}} p>.05$.

SSRT in the discrete STOP condition when computed at $\mathrm{FCz}(r$ ${ }_{(18)}=0.52$, corrected $\left.p=.04, \mathrm{CI}_{95}[0.10,0.79]\right)$ and $\mathrm{Cz}$ sites $(r$ ${ }_{(18)}=0.60$, corrected $p=.01, \mathrm{CI}_{95}[0.20,0.83]$ ), whereas Power peak amplitude was significantly correlated to SSRT in the rhythmic STOP condition at $\mathrm{FCz}\left(r_{(18)}=-0.53\right.$, corrected $p=.04, \mathrm{CI}_{95}[-0.79$, $-0.09])$. No other Power-behavior correlation was significant.

\section{Discussion}

Prior work has investigated the scalp activity evoked by the successful cancellation of a prepared-discrete action (Huster et al., 2013). As inhibitory processes are supposed to generalize across action types, we tested whether EEG correlates of action cancellation were also observed when stopping an ongoing-rhythmic action. Comparing discrete and rhythmic movements, which are fundamentally distinct in terms of their dynamics (Hogan and Sternad, 2007) and engage distinct brain areas (Schaal et al., 2004), proved a fruitful strategy to investigate the assumption that action inhibition is an action-independent process.

\subsection{About unitary of action inhibition}

The behavioral analysis indicated that the SSRTs did not differ between the discrete and rhythmic tasks and were within the range found in previous studies, including various discrete responses (e.g., Boucher et al., 2007; Kok et al., 2004; Krämer et al., 2011; Montanari et al., 2017). Critically, the absence of a correlation between the 20 participants' inhibitory performances in the discrete and rhythmic tasks, a finding consistent with previous work (Hervault et al., 2019), challenges the notion that the processes inhibiting actions are fundamentally task-independent. This finding is strengthened by the strong positive correlation between blocks of rhythmic tasks, emphasizing that the absence of a correlation between the discrete and rhythmic task does not simply reflect weak performance reproducibility. It rather signifies that genuinely distinct processes, at least partly so, are implicated in the inhibition of discrete and rhythmic actions. The EEG analysis corroborated this conclusion: Although the STOP signals evoked a distinctive N2/P3-complex in the time domain and, concurrently, a Delta/Theta power increase in the frequency domain in both tasks, these inhibi- tion-related EEG patterns differed significantly between tasks and, crucially, did so in a functionally relevant manner.

N2 and P3 waves were both evoked in the two tasks. Strikingly though, a later P3 onset latency was associated with a longer SSRT in the discrete task, but not in the rhythmic task. In contrast, a larger N2/ P3 peak-to-peak amplitude was associated with a shorter SSRT in the rhythmic task, but not in the discrete one. For the discrete task, these findings confirm the P3 - SSRT correlation previously reported, with an earlier SSRTs being associated with higher P3s (e.g., Huster et al., 2014), as well as earlier P3s (Anguera and Gazzaley, 2012; Wessel, 2018; Wessel and Aron, 2015); the reported correlation values were more inconsistent for the N2 - SSRT relation (e.g., Anguera and Gazzaley, 2012; Raud and Huster, 2017; Senderecka, 2016). Thus, N2 and P3 may act as partially dissociated correlates of inhibition processes, their importance varying as a function of the type of movement to revise. Such functional partial dissociation between discrete-task conditions was previously advocated by isolating the neural generators underlying the occurrence of two ERP waves in a combined GO/NoGO - stop-signal task. The anterior part of the mid-cingulate cortex was identified as the origin of the N2 differences between conditions (GO, NoGO, STOP), whereas the inferior frontal gyrus as well as the posterior part of the mid-cingulate cortex were identified as at the origin of the P3 differences (Enriquez-Geppert et al., 2010; Huster et al., 2010). In another framework, an fMRI frontocentral dissociation between discrete and continuous action generation has been reported in the mid-cingulate area (Schaal et al., 2004). While further investigation is needed to interpret these activations in the context of action inhibition, this dissociation may play a role in the differential involvement of $\mathrm{N} 2$ and $\mathrm{P} 3$ waves in action inhibition.

Our results also indicate that time-frequency power elicited by the STOP signal in the Delta/Theta frequency range differed between the two tasks, this power increase being significantly related to inhibitory performance in both situations. Therefore, a STOP-signal-related Delta/Theta power increase can be viewed as more generically engaged in inhibitory processes. Indeed, a Delta/Theta power increase has been associated with the conflictual/decisional requirement of tasks in various situations (Cavanagh et al., 2012; Harmony, 2013). Our findings are thus in line with the idea that action inhibition pertains to a conflict management between the regular main stimulus (GO or CONTINUE) 
and the occasional STOP signal. Taken together, the present findings demonstrate that SSRTs and related frontocentral EEG patterns differed between cancelling a prepared-discrete action and stopping an ongoing-rhythmic action, suggesting that the neural processes underlying inhibitory control are modulated as a function of action type.

\subsection{Different inhibitory subprocesses}

The STOP-related Delta/Theta power increase was visible in the two STOP conditions whereas the N2 and P3 ERP waves were more specifically engaged in rhythmic action stopping and discrete action cancelling, respectively. This dissociation between the STOP-signal evoked ERPs allows for different interpretations following different conceptualizations of cognitive functioning in inhibitory control.

First, this dissociation may indicate differences in conflict processing between the two tasks. N2 and P3 waves are classically observed in conflictual situations, such as action inhibition (Ramautar et al., 2004), interference monitoring (Groom and Cragg, 2015), or task switching (Kopp et al., 2020). In GO/NoGO and stop-signal tasks, conflict arises whenever infrequent responses are required in the face of frequent responses (Braver et al., 2001; Mirabella, 2014). More specifically, high conflict occurs when infrequent STOP responses have to overcome the prepotency of frequent responses. In discrete inhibition tasks, previous work has shown that N2 indicates the occurrence of the conflict in information processing, whereas P3 relates to the resolution of the conflict by inhibiting the action (Enriquez-Geppert et al., 2010; Randall and Smith, 2011). Interpreting our results along this line, conflict detection might be more crucially engaged in stopping an ongoing action (as reflected by a larger N2 negativity), while conflict resolution would be so in cancelling a preplanned action (as reflected by a higher P3 wave). Still, the overall balance between the two conflict-related subprocesses may result in similar inhibition latencies, as reflected by the statistically indistinguishable SSRTs. The analysis of the occipital Oz channel revealed no significant difference between the tasks regarding the early visual N1 wave, suggesting that the two tasks did not differ regarding early attentional processes, but did so for later cognitive control engagement. The higher P3 amplitude observed in the discrete task may reflect the allocation of more resources in resolving the conflict, when the GO vs. STOP response is more conflictual than the CONTINUE vs. STOP response. This functional dissociation can find support in prior work requiring prepared-discrete actions (Enriquez-Geppert et al., 2010; Randall and Smith, 2011). To extend its plausibility in the context of ongoing-continuous actions, further investigation is needed manipulating the requirement associated to the infrequent signal (i.e., STOP, CONTINUE).

Second, the observed EEG dissociation between discrete movement cancellation and rhythmic movement stopping may reflect task-specific differences in brain predictive processing. Assuming that the brain is a predictive organ, cortical responses can be seen as transient expressions of prediction error (Friston, 2005). The P3 wave, which commonly follows low-probability signal occurrence, would index the update of a mental representation of the environment (Polich, 2007). Comparably, motor control has been modeled as a dual-representation system comparing the predicted and the actual states of the effector (Synofzik et al., 2008). Thus, P3 would reflect prediction error processing that is common to both sensorimotor and cognitive functions. In the case of movement generation, multiple studies have distinguished discrete and rhythmic continuous actions on the basis of the engaged representation of time (Ivry and Spencer, 2004; Zelaznik et al., 2002). Briefly, the timing control of discrete actions requires an explicit process, that is, it depends on an explicit representation of the passage of time. In contrast, the timing of continuous actions is implicit as the temporal properties of the action are presumably emergent (i.e., an explicit representation of time does not directly guide performance). This fundamental distinction between the two action types may, in the present experiment, re- sult in distinct mental predictions accompanying the processing of the GO and the CONTINUE stimuli (e.g., related to the temporal dimensions of the movement, Krigolson et al., 2008). The unexpected STOP signal causes a prediction error being indexed by P3 occurrence. Given that the STOP signal probability (25\%) was the same between the two tasks, as was the mean SOA, the differences in P3 measures may imply a prediction error modulation due to the discrete or continuous type of the action. Indeed, the explicit representation of time in the discrete task is plausibly accompanied by a "strong" prediction related to the movement execution. In contrast, the implicit timing processing in the rhythmic task can be accompanied by a "weak" prediction. Thus, the prediction violation evoked by the STOP signal might be extended in the discrete STOP trial as compared to the rhythmic STOP trial, as suggested by a higher P3 amplitude in the discrete condition. To further investigate this hypothesis, future EEG studies might manipulate the "prediction level" by varying the probability of the STOP signal (Dimoska and Johnstone, 2008) and/or by varying the SOA between the main stimulus and the STOP signal, in the two action types.

Third, another account on inhibitory control posits that performance in a stop-signal task encompasses both "reactive inhibition" and "proactive inhibition". Thus, participants may adjust the response speed to the main stimulus when anticipating the occurrence of the improbable STOP signal (Verbruggen and Logan, 2009b). In the discrete task, these strategic adaptations allow adjusting the preparation of the response to the GO stimulus. In the rhythmic task, such adaptation appears unlikely, as there is no response preparation to adjust when the CONTINUE stimulus appears while the movement is ongoing. In addition, no proactive slowing of the ongoing rhythmic movement was shown in the present study. Thus, action inhibition might involve both reactive and proactive processes in the discrete cancellation, whereas only reactive processes would be engaged in the rhythmic stopping. The proactive process, which modifies the neural implementation of inhibitory control (Kenemans, 2015; Leunissen et al., 2016), could thus cause the observed differences in brain activity engaged in the two tasks. To examine this tentative explanation, further EEG studies should manipulate cued-based proactive engagement (Verbruggen and Logan, 2009b) or capture the proactive/reactive balance through a kinematic movement analysis (Benedetti et al., 2020; Schultz et al., 2021).

\subsection{Implications}

Inhibitory control is known to rely on a fronto-basal ganglia brain network (Aron, 2011; Lofredi et al., 2021). Recent studies found this network to become active when facing various unexpected events, leading to a "unified theory" of inhibition (Wessel and Aron, 2017). Our findings are incompatible with the view of action inhibition as a unitary construct but are readily accommodated in a framework holding that different components of a unique fronto-basal ganglia inhibition network are implicated in inhibition in an action-type dependent manner. Thus, given a potential dissociation within the cingulate cortex enrollment (see also section 4.1.), the relative engagement of different parts of the inhibitory network may vary as a function of the action type. Along this line, the fronto-basal ganglia brain network was recently shown to be differentially engaged depending on the task constraints, such as facing STOP or NoGO signals (Raud et al., 2020).

The activation of different neural subprocesses depending on action type has two important implications. The first is technological. Devices such as a wheelchair, a robotic arm, or a drone can be controlled through different kinds of movements via brain-computer interfaces (BCI). Chikara and Ko (2019) suggested that the neural activity related to inhibition, particularly the P3 wave, can be used as a stop signal. However, given the assumption of dissociate processes of action inhibition, cancelling a prepared-discrete response (e.g., grasping the wrong object) and stopping an ongoing-continuous action (e.g., wheelchair displacement) might require dissociate neural command based on P3 
and N2/P3 peak-to-peak amplitude, respectively. The second implication is methodological and clinical. While the "discrete" procedure for SSRT estimation leads classically to a single across-trials SSRT per participant, ongoing-continuous actions offer a way of measuring single-trial SSRTs that would not depend on an inhibition function inferred statistically. This within-trial variability would be of particular interest for assessing (action) inhibition in troubles such as Attention-Deficit/Hyperactivity Disorder (ADHD) (Morein-Zamir et al., 2008). This disorder has been associated with longer SSRT and specific ERP signatures in discrete-response cancellation tasks (Bekker et al., 2005). Nonetheless, given the temporal variability characteristic of $\mathrm{ADHD}$, a more variable inhibition latency might be a singular characteristic of the ADHD population, rather than a longer latency (Castellanos et al., 2006; Lijffijt et al., 2005). Consequently, tasks allowing for within-trial SSRT determination, such as the rhythmic task used here, could be instrumental in revealing an inhibitory deficiency in ADHD.

\section{Conclusion}

The present article raises a key question about inhibitory control: Are the neural mechanisms underlying inhibition action-independent or action-specific? We addressed this issue by comparing cancelling a prepared-discrete response and stopping an ongoing-rhythmic action. Behavioral analysis provided a first indication that inhibition of the two action types is controlled differently. Consistent therewith, EEG analysis further revealed that the components of the frontocentral N2/ P3-complex are implicated in inhibition in an action-type dependent manner. Extending our understanding of inhibition requires the identification of the task constraints that set inhibition "types" apart versus those that do not, and to spell out principles allowing for an unambiguous delineation of such types in neural space.

\section{Author contributions}

M.H., PG.Z., JC.B. and R.H. are responsible for the study concept and design. M.H. acquired the data. The analysis and interpretation of data were carried out by M.H., PG.Z. and R.H. The manuscript was drafted by M.H., PG.Z. and R.H. All authors gave approval of the final submitted version.

\section{Funding}

This research did not receive any specific grant from funding agencies in the public, commercial, or not-for-profit sectors.

\section{Uncited references}

$$
; ;, \text {. }
$$

\section{Declaration of competing interest}

There are no conflicting interests.

\section{Acknowledgements}

All authors gave approval of the final submitted version. The authors wish to thank all participants in this research.

\section{References}

Alegre, M., Alvarez-Gerriko, I., Valencia, M., Iriarte, J., Artieda, J., 2008. Oscillatory changes related to the forced termination of a movement. Clin. Neurophysiol. 119 (2), 290-300. https://doi.org/10.1016/j.clinph.2007.10.017.

Anguera, J.A., Gazzaley, A., 2012. Dissociation of motor and sensory inhibition processes in normal aging. Clin. Neurophysiol. 123 (4), 730-740. https://doi.org/10.1016/ j.clinph.2011.08.024.
Aron, A.R., 2007. The neural basis of inhibition in cognitive control. Neuroscientist: Rev. J. Bring. Neurobiol. Neurol. Psychaiatr. 13 (3), 214-228. https://doi.org/10.1177/ 1073858407299288.

Aron, A.R., 2011. From reactive to proactive and selective control: developing a richer model for stopping inappropriate responses. Biol. Psychiatr. 69 (12), e55-e68. https://doi.org/10.1016/j.biopsych.2010.07.024.

Band, G.P., van Boxtel, G.J., 1999. Inhibitory motor control in stop paradigms: review and reinterpretation of neural mechanisms. Acta Psychol. 101 (2-3), 179-211.

Bari, A., Robbins, T.W., 2013. Inhibition and impulsivity: behavioral and neural basis of response control. Prog. Neurobiol. 108, 44-79. https://doi.org/10.1016/ j.pneurobio.2013.06.005.

Bekker, E.M., Overtoom, C.C.E., Kooij, J.J.S., Buitelaar, J.K., Verbaten, M.N., Kenemans, J.L., 2005. Disentangling deficits in adults with attention-deficit/hyperactivity disorder. Arch. Gen. Psychiatr. 62 (10), 1129-1136. https://doi.org/10.1001/ archpsyc.62.10.1129.

Bell, A.J., Sejnowski, T.J., 1995. An information-maximization approach to blind separation and blind deconvolution. Neural Comput. 7 (6), 1129-1159. https:// doi.org/10.1162/neco.1995.7.6.1129.

Benedetti, V., Gavazzi, G., Giovannelli, F., Bravi, R., Giganti, F., Minciacchi, D., Mascalchi, M., Cincotta, M., Viggiano, M.P., 2020. Mouse tracking to explore motor inhibition processes in go/No-go and stop signal tasks. Brain Sci. 10 (7), 464. https://doi.org/ 10.3390/brainsci10070464.

Boucher, L., Stuphorn, V., Logan, G.D., Schall, J.D., Palmeri, T.J., 2007. Stopping eye and hand movements: are the processes independent? Percept. Psychophys. 69 (5), 785-801. https://doi.org/10.3758/BF03193779.

Braver, T.S., Barch, D.M., Gray, J.R., Molfese, D.L., Snyder, A., 2001. Anterior cingulate cortex and response conflict: effects of frequency, inhibition and errors. Cerebral Cortex (New York, N.Y. 11 (9), 825-836. 1991. https://doi.org/10.1093/cercor/ 11.9.825.

Bryden, M.P., 1977. Measuring handedness with questionnaires. Neuropsychologia 15 (4-5), 617-624. https://doi.org/10.1016/0028-3932(77)90067-7.

Castellanos, F.X., Sonuga-Barke, E.J.S., Milham, M.P., Tannock, R., 2006. Characterizing cognition in ADHD: beyond executive dysfunction. Trends Cognit. Sci. 10 (3), 117-123. https://doi.org/10.1016/j.tics.2006.01.011.

Cavanagh, J.F., Zambrano-Vazquez, L., Allen, J.J.B., 2012. Theta lingua franca: a common mid-frontal substrate for action monitoring processes. Psychophysiology 49 (2), 220-238. https://doi.org/10.1111/j.1469-8986.2011.01293.x.

Chikara, R.K., Ko, L.-W., 2019. Neural activities classification of human inhibitory control using hierarchical model. Sensors 19 (17), 3791. https://doi.org/10.3390/ s19173791.

Chikara, R.K., Perumal, R., Ko, L.-W., Chen, H., 2014. EEG dynamics in inhibition of lefthand and right-hand responses during auditory stop-signal task. In: 2014 IEEE Symposium on Computational Intelligence, Cognitive Algorithms, Mind, and Brain (CCMB). pp. 115-120. https://doi.org/10.1109/CCMB.2014.7020703.

Cohen, J., 1988. In: reprint (Ed.), Statistical Power Analysis for the Behavioral Sciences. Psychology Press.

Cohen, M.X., 2014. Analyzing Neural Time Series Data - Theory and Practice, first ed. MIT Press.

Delorme, A., Makeig, S., 2004. EEGLAB: an open source toolbox for analysis of single-trial EEG dynamics including independent component analysis. J. Neurosci. Methods 134 (1), 9-21. https://doi.org/10.1016/j.jneumeth.2003.10.009.

Diamond, A., 2013. Executive functions. Annu. Rev. Psychol. 64 (1), 135-168. https:// doi.org/10.1146/annurev-psych-113011-143750.

Dimoska, A., Johnstone, S.J., 2008. Effects of varying stop-signal probability on ERPs in the stop-signal task: do they reflect variations in inhibitory processing or simply novelty effects? Biol. Psychol. 77 (3), 324-336. https://doi.org/10.1016/ j.biopsycho.2007.11.005.

Enriquez-Geppert, S., Konrad, C., Pantev, C., Huster, R.J., 2010. Conflict and inhibition differentially affect the N200/P300 complex in a combined go/nogo and stop-signal task. Neuroimage 51 (2), 877-887. https://doi.org/10.1016/ j.neuroimage.2010.02.043.

Faul, F., Erdfelder, E., Buchner, A., Lang, A.-G., 2009. Statistical power analyses using G* Power 3.1: tests for correlation and regression analyses. Behav. Res. Methods 41 (4), 1149-1160. https://doi.org/10.3758/BRM.41.4.1149.

Friston, K., 2005. A theory of cortical responses. Phil. Trans. Biol. Sci. 360 (1456), 815-836. https://doi.org/10.1098/rstb.2005.1622.

González-Villar, A.J., Bonilla, F.M., Carrillo-de-la-Peña, M.T., 2016. When the brain simulates stopping: neural activity recorded during real and imagined stop-signal tasks. Cognit. Affect Behav. Neurosci. 16 (5), 825-835. https://doi.org/10.3758/ s13415-016-0434-3.

Groom, M.J., Cragg, L., 2015. Differential modulation of the N2 and P3 event-related potentials by response conflict and inhibition. Brain Cognit. 97, 1-9. https://doi.org/ 10.1016/j.bandc.2015.04.004.

Hannah, R., Aron, A.R., 2021. Towards real-world generalizability of a circuit for actionstopping. Nat. Rev. Neurosci. 22 (9), 538-552. https://doi.org/10.1038/s41583-02100485-1.

Harmony, T., 2013. The functional significance of delta oscillations in cognitive processing. Front. Integr. Neurosci. 7. https://doi.org/10.3389/fnint.2013.00083.

Hatta, A., Nishihira, Y., Kaneda, T., Wasaka, T., Kida, T., Kuroiwa, K., Akiyama, S., 2003. Somatosensory event-related potentials (ERPs) associated with stopping ongoing movement. Percept. Mot. Skills 97 (3 Pt 1), 895-904. https://doi.org/10.2466/ pms.2003.97.3.895.

Hermes, D., Siero, J.C.W., Aarnoutse, E.J., Leijten, F.S.S., Petridou, N., Ramsey, N.F., 2012. Dissociation between neuronal activity in sensorimotor cortex and hand movement revealed as a function of movement rate. J. Neurosci. 32 (28), 9736-9744. https://doi.org/10.1523/JNEUROSCI.0357-12.2012. 
Hervault, M., Huys, R., Farrer, C., Buisson, J.C., Zanone, P.G., 2019. Cancelling discrete and stopping ongoing rhythmic movements: do they involve the same process of motor inhibition? Hum. Mov. Sci. 64, 296-306. https://doi.org/10.1016/ j.humov.2019.02.010.

Hillyard, S.A., Vogel, E.K., Luck, S.J., 1998. Sensory gain control (amplification) as a mechanism of selective attention: electrophysiological and neuroimaging evidence. Phil. Trans. Biol. Sci. 353 (1373), 1257-1270.

Hogan, N., Sternad, D., 2007. On rhythmic and discrete movements: reflections, definitions and implications for motor control. Exp. Brain Res. 181 (1), 13-30. https://doi.org/10.1007/s00221-007-0899-y.

Huster, R.J., Enriquez-Geppert, S., Lavallee, C.F., Falkenstein, M., Herrmann, C.S., 2013. Electroencephalography of response inhibition tasks: functional networks and cognitive contributions. Int. J. Psychophysiol.: Off. J. Int. Org. Psychophysiol. 87 (3), 217-233. https://doi.org/10.1016/j.ijpsycho.2012.08.001.

Huster, R.J., Messel, M.S., Thunberg, C., Raud, L., 2020. The P300 as marker of inhibitory control - fact or fiction? Cortex. https://doi.org/10.1016/j.cortex.2020.05.021.

Huster, R.J., Plis, S.M., Lavallee, C.F., Calhoun, V.D., Herrmann, C.S., 2014. Functional and effective connectivity of stopping. Neuroimage 94, 120-128. https://doi.org/ 10.1016/j.neuroimage.2014.02.034.

Huster, R.J., Westerhausen, R., Pantev, C., Konrad, C., 2010. The role of the cingulate cortex as neural generator of the N200 and P300 in a tactile response inhibition task. Hum. Brain Mapp. 31 (8), 1260-1271. https://doi.org/10.1002/hbm.20933.

Huys, R., Studenka, B.E., Rheaume, N.L., Zelaznik, H.N., Jirsa, V.K., 2008. Distinct timing mechanisms produce discrete and continuous movements. PLoS Comput. Biol. 4 (4), e1000061. https://doi.org/10.1371/journal.pcbi.1000061.

Hynd, M., Soh, C., Rangel, B.O., Wessel, J.R., 2020. Latency and amplitude of the stopsignal P3 event-related potential are related to inhibitory GABAa activity in primary motor cortex. bioRxiv. 2020.09.15.298711. https://doi.org/10.1101/ 2020.09.15.298711.

Ivry, R.B., Spencer, R.M.C., 2004. The neural representation of time. Curr. Opin. Neurobiol. 14 (2), 225-232. https://doi.org/10.1016/j.conb.2004.03.013.

Kenemans, J.L., 2015. Specific proactive and generic reactive inhibition. Neurosci. Biobehav. Rev. 56, 115-126. https://doi.org/10.1016/j.neubiorev.2015.06.011.

Kok, A., Ramautar, J.R., De Ruiter, M.B., Band, G.P.H., Ridderinkhof, K.R., 2004. ERP components associated with successful and unsuccessful stopping in a stop-signal task. Psychophysiology 41 (1), 9-20. https://doi.org/10.1046/j.14698986.2003.00127.x.

Kopp, B., Steinke, A., Visalli, A., 2020. Cognitive flexibility and N2/P3 event-related brain potentials. Sci. Rep. 10 (1), 9859. https://doi.org/10.1038/s41598-020-66781-5.

Krämer, U.M., Knight, R.T., Münte, T.F., 2011. Electrophysiological evidence for different inhibitory mechanisms when stopping or changing a planned response. J. Cognit. Neurosci. 23 (9), 2481-2493. https://doi.org/10.1162/jocn.2010.21573.

Krigolson, O.E., Holroyd, C.B., Van Gyn, G., Heath, M., 2008. Electroencephalographic correlates of target and outcome errors. Exp. Brain Res. 190 (4), 401-411. https:// doi.org/10.1007/s00221-008-1482-x.

Kusztor, A., Raud, L., Juel, B.E., Nilsen, A.S., Storm, J.F., Huster, R.J., 2019. Sleep deprivation differentially affects subcomponents of cognitive control. Sleep 42 (4). https://doi.org/10.1093/sleep/zsz016.

Lansbergen, M.M., Böcker, K.B.E., Bekker, E.M., Kenemans, J.L., 2007. Neural correlates of stopping and self-reported impulsivity. Clin. Neurophysiol.: Off. J. Int. Feder. Clin. Neurophysiol. 118 (9), 2089-2103. https://doi.org/10.1016/j.clinph.2007.06.011.

Lavallee, C.F., Meemken, M.T., Herrmann, C.S., Huster, R.J., 2014. When holding your horses meets the deer in the headlights: time-frequency characteristics of global and selective stopping under conditions of proactive and reactive control. Front. Hum. Neurosci. 8. https://doi.org/10.3389/fnhum.2014.00994.

Leunissen, I., Coxon, J.P., Swinnen, S.P., 2016. A proactive task set influences how response inhibition is implemented in the basal ganglia. Hum. Brain Mapp. 37 (12), 4706-4717. https://doi.org/10.1002/hbm.23338.

Lijffijt, M., Kenemans, J.L., Verbaten, M.N., van Engeland, H., 2005. A meta-analytic review of stopping performance in attention-deficit/hyperactivity disorder: deficient inhibitory motor control? J. Abnorm. Psychol. 114 (2), 216-222. https://doi.org/ 10.1037/0021-843X.114.2.216.

Lofredi, R., Auernig, G.C., Irmen, F., Nieweler, J., Neumann, W.-J., Horn, A., Schneider, G.-H., Kühn, A.A., 2021. Subthalamic stimulation impairs stopping of ongoing movements. Brain 144 (1), 44-52. https://doi.org/10.1093/brain/awaa341.

Logan, G.D., Cowan, W.B., 1984. On the ability to inhibit thought and action: a theory of an act of control. Psychol. Rev. 91 (3), 295-327. https://doi.org/10.1037/0033295X.91.3.295.

Lopez-Calderon, J., Luck, S.J., 2014. ERPLAB: an open-source toolbox for the analysis of event-related potentials. Front. Hum. Neurosci. 8. https://doi.org/10.3389/ fnhum.2014.00213.

Luck, S.J., 2014. An Introduction to the Event-Related Potential Technique. MIT Press.

Maris, E., Oostenveld, R., 2007. Nonparametric statistical testing of EEG- and MEG-data. J. Neurosci. Methods 164 (1), 177-190. https://doi.org/10.1016/ j.jneumeth.2007.03.024.

Mirabella, G., 2014. Should I stay or should I go? Conceptual underpinnings of goaldirected actions. Front. Syst. Neurosci. 8, 6. https://doi.org/10.3389/ fnsys.2014.00206.

Miyake, A., Friedman, N.P., Emerson, M.J., Witzki, A.H., Howerter, A., Wager, T.D., 2000. The unity and diversity of executive functions and their contributions to complex "frontal lobe" tasks: a latent variable analysis. Cognit. Psychol. 41 (1), 49-100. https://doi.org/10.1006/cogp.1999.0734.

Montanari, R., Giamundo, M., Brunamonti, E., Ferraina, S., Pani, P., 2017. Visual salience of the stop-signal affects movement suppression process. Exp. Brain Res. 235 (7), 2203-2214. https://doi.org/10.1007/s00221-017-4961-0.

Morein-Zamir, S., Chua, R., Franks, I., Nagelkerke, P., Kingstone, A., 2006. Measuring online volitional response control with a continuous tracking task. Behav. Res. Methods 38 (4), 638-647. https://doi.org/10.3758/BF03193896.

Morein-Zamir, S., Hommersen, P., Johnston, C., Kingstone, A., 2008. Novel measures of response performance and inhibition in children with ADHD. J. Abnorm. Child Psychol. 36 (8), 1199-1210. https://doi.org/10.1007/s10802-008-9243-7.

Morein-Zamir, S., Nagelkerke, P., Chua, R., Franks, I., Kingstone, A., 2004. Inhibiting prepared and ongoing responses: is there more than one kind of stopping? Psychon. Bull. Rev. 11 (6), 1034-1040. https://doi.org/10.3758/BF03196733.

Pion-Tonachini, L., Kreutz-Delgado, K., Makeig, S., 2019. ICLabel: an automated electroencephalographic independent component classifier, dataset, and website. Neuroimage 198, 181-197. https://doi.org/10.1016/j.neuroimage.2019.05.026.

Polich, J., 2007. Updating P300: an integrative theory of P3a and P3b. Clin. Neurophysiol. : Off. J. Int. Feder. Clin. Neurophysiol. 118 (10), 2128-2148. https:// doi.org/10.1016/j.clinph.2007.04.019.

Ramautar, J.R., Kok, A., Ridderinkhof, K.R., 2004. Effects of stop-signal probability in the stop-signal paradigm: the N2/P3 complex further validated. Brain Cognit. 56 (2), 234-252. https://doi.org/10.1016/j.bandc.2004.07.002

Ramautar, J.R., Kok, A., Ridderinkhof, K.R., 2006. Effects of stop-signal modality on the N2/P3 complex elicited in the stop-signal paradigm. Biol. Psychol. 72 (1), 96-109. https://doi.org/10.1016/j.biopsycho.2005.08.001.

Randall, W.M., Smith, J.L., 2011. Conflict and inhibition in the cued-Go/NoGo task. Clin. Neurophysiol. 122 (12), 2400-2407. https://doi.org/10.1016/j.clinph.2011.05.012.

Raud, L., Huster, R.J., 2017. The temporal dynamics of response inhibition and their modulation by cognitive control. Brain Topogr. 30 (4), 486-501. https://doi.org/ 10.1007/s10548-017-0566-y.

Raud, L., Westerhausen, R., Dooley, N., Huster, R.J., 2020. Differences in unity: the go/nogo and stop signal tasks rely on different mechanisms. Neuroimage 210,116582 https://doi.org/10.1016/j.neuroimage.2020.116582.

Sawilowsky, S., 2009. New Effect Size Rules of Thumb. Theoretical and Behavioral Foundations of Education Faculty Publications. https://digitalcommons.wayne.edu/ coe_tbf $/ 4$.

Schaal, S., Sternad, D., Osu, R., Kawato, M., 2004. Rhythmic arm movement is not discrete. Nat. Neurosci. 7 (10), 1136-1143. https://doi.org/10.1038/nn1322.

Schall, J.D., Palmeri, T.J., Logan, G.D., 2017. Models of Inhibitory Control, vol. 372. Philosophical Transactions of the Royal Society of London. Series B, Biological Sciences (1718). https://doi.org/10.1098/rstb.2016.0193.

Schultz, K.E., Denning, D., Hufnagel, V., Swann, N., 2021. Stopping a Continuous Movement: A Novel Approach to Investigating Motor Control. BioRxiv. 2021.04.08.439070. https://doi.org/10.1101/2021.04.08.439070.

Seeber, M., Scherer, R., Müller-Putz, G.R., 2016. EEG oscillations are modulated in different behavior-related networks during rhythmic finger movements. J. Neurosci. 36 (46), 11671-11681. https://doi.org/10.1523/JNEUROSCI.1739-16.2016.

Senderecka, M., 2016. Threatening visual stimuli influence response inhibition and error monitoring: an event-related potential study. Biol. Psychol. 113, 24-36. https:// doi.org/10.1016/j.biopsycho.2015.11.003.

Sosnik, R., Chaim, E., Flash, T., 2015. Stopping is not an option: the evolution of unstoppable motion elements (primitives). J. Neurophysiol. 114 (2), 846-856. https://doi.org/10.1152/jn.00341.2015.

Spencer, R.M.C., Zelaznik, H.N., Diedrichsen, J., Ivry, R.B., 2003. Disrupted timing of discontinuous but not continuous movements by cerebellar lesions. Science (New York, N.Y.) 300 (5624), 1437-1439. https://doi.org/10.1126/science.1083661.

Synofzik, M., Vosgerau, G., Newen, A., 2008. Beyond the comparator model: a multifactorial two-step account of agency. Conscious. Cognit. 17 (1), 219-239. https://doi.org/10.1016/j.concog.2007.03.010.

Toma, K., Mima, T., Matsuoka, T., Gerloff, C., Ohnishi, T., Koshy, B., Andres, F., Hallett, M., 2002. Movement rate effect on activation and functional coupling of motor cortical areas. J. Neurophysiol. 88 (6), 3377-3385. https://doi.org/10.1152/ jn.00281.2002.

Tschuemperlin, R.M., Stein, M., Batschelet, H.M., Moggi, F., Soravia, L.M., 2019. Learning to resist the urge: a double-blind, randomized controlled trial investigating alcoholspecific inhibition training in abstinent patients with alcohol use disorder. Trials 20 (1), 402. https://doi.org/10.1186/s13063-019-3505-2.

Vahid, A., Mückschel, M., Neuhaus, A., Stock, A.-K., Beste, C., 2018. Machine learning provides novel neurophysiological features that predict performance to inhibit automated responses. Sci. Rep. 8 (1), 16235. https://doi.org/10.1038/s41598-01834727-7.

Van Voorhis, A.C., Kent, J.S., Kang, S.S., Goghari, V.M., MacDonald, A.W., Sponheim, S.R., 2019. Abnormal neural functions associated with motor inhibition deficits in schizophrenia and bipolar disorder. Hum. Brain Mapp. 40 (18), 5397-5411. https:// doi.org/10.1002/hbm.24780.

Verbruggen, F., Aron, A.R., Band, G.P., Beste, C., Bissett, P.G., Brockett, A.T., Brown, J.W., Chamberlain, S.R., Chambers, C.D., Colonius, H., Colzato, L.S., Corneil, B.D., Coxon, J.P., Dupuis, A., Eagle, D.M., Garavan, H., Greenhouse, I., Heathcote, A., Huster, R.J., Boehler, C.N., 2019. A consensus guide to capturing the ability to inhibit actions and impulsive behaviors in the stop-signal task. Elife 8, e46323. https://doi.org/10.7554/ eLife.46323.

Verbruggen, F., Logan, G.D., 2009a. Models of response inhibition in the stop-signal and stop-change paradigms. Neurosci. Biobehav. Rev. 33 (5), 647-661. https://doi.org/ 10.1016/j.neubiorev.2008.08.014.

Verbruggen, F., Logan, G.D., 2009b. Proactive adjustments of response strategies in the stop-signal paradigm. J. Exp. Psychol. Hum. Percept. Perform. 35 (3), 835-854. https://doi.org/10.1037/a0012726.

Vogel, E.K., Luck, S.J., 2000. The visual N1 component as an index of a discrimination process. Psychophysiology 37 (2), 190-203.

Waller, D.A., Hazeltine, E., Wessel, J.R., 2019. Common neural processes during actionstopping and infrequent stimulus detection: the frontocentral P3 as an index of 
generic motor inhibition. Int. J. Psychophysiol. https://doi.org/10.1016/ j.ijpsycho.2019.01.004.

Wessel, J.R., 2018. Prepotent motor activity and inhibitory control demands in different variants of the go/no-go paradigm. Psychophysiology 55 (3), e12871. https:// doi.org/10.1111/psyp.12871.

Wessel, J.R., Aron, A.R., 2013. Unexpected events induce motor slowing via a brain mechanism for action-stopping with global suppressive effects. J. Neurosci. 33 (47), 18481-18491. https://doi.org/10.1523/JNEUROSCI.3456-13.2013.

Wessel, J.R., Aron, A.R., 2015. It's not too late: the onset of the frontocentral P3 indexes successful response inhibition in the stop-signal paradigm. Psychophysiology 52 (4), 472-480. https://doi.org/10.1111/psyp.12374.

Wessel, J.R., Aron, A.R., 2017. On the globality of motor suppression: unexpected events and their influence on behavior and cognition. Neuron 93 (2), 259-280. https:// doi.org/10.1016/j.neuron.2016.12.013.

Wiegel, P., Kurz, A., Leukel, C., 2020. Evidence that distinct human primary motor cortex circuits control discrete and rhythmic movements. J. Physiol. 598 (6), 1235-1251. https://doi.org/10.1113/JP278779.

Woldorff, M.G., 1993. Distortion of ERP averages due to overlap from temporally adjacent ERPs: analysis and correction. Psychophysiology 30 (1), 98-119. https://doi.org/ 10.1111/j.1469-8986.1993.tb03209.x.

Zelaznik, H.N., Spencer, R.M.C., Ivry, R.B., 2002. Dissociation of explicit and implicit timing in repetitive tapping and drawing movements. J. Exp. Psychol. Hum. Percept. Perform. 28 (3), 575-588. https://doi.org/10.1037//0096-1523.28.3.575. 